\title{
Hip muscular strength balance is associated with running economy in recreationally-trained endurance runners
}

\author{
Wallace A. Silva ${ }^{1}$, Claudio Andre B. de Lira ${ }^{\text {Corresp., }}{ }^{2}$, Rodrigo L. Vancini ${ }^{3}$, Marilia S. Andrade ${ }^{\text {Corresp. } 1}$ \\ 1 Departamento de Fisiologia, Universidade Federal de São Paulo, São Paulo, São Paulo, Brazil \\ 2 Faculdade de Educação Física e Dança, Universidade Federal de Goiás, Goiânia, Goiás, Brazil \\ 3 Centro de Educação Física e Desportos, Universidade Federal do Espírito Santo, Vitória, Espírito Santo, Brazil \\ Corresponding Authors: Claudio Andre B. de Lira, Marilia S. Andrade \\ Email address: andre.claudio@gmail.com, marilia1707@gmail.com
}

Background. The percentage of sustained maximal oxygen uptake and the running economy are important factors that determine the running success of endurance athletes. Running economy is defined as the oxygen uptake required to run at a given speed and depends on metabolic, cardiorespiratory, biomechanical, neuromuscular, and anthropometric factors. With regards to anthropometric characteristics, total body mass seems to be a crucial factor for the running economy. Moreover, neuromuscular components, especially knee muscular strength and the strength balance ratio, also seem to be critical for the running economy. In addition to knee muscle strength, hip muscle strength is also an important contributor to running performance on level or hilly ground. However, the relationship between running economy and the hip muscles is unknown. Thus the aim of the present study was to verify whether hip flexor and extensor isokinetic peak torque, the isokinetic strength balance ratio, total body mass and fat free mass were associated with running economy in both sexes and to compare sex differences in physical fitness and isokinetic strength characteristics. Methods. A total of 24 male (31.0 \pm 7.7 years, $176.2 \pm 7.3 \mathrm{~cm}$, and $70.4 \pm 8.4 \mathrm{~kg})$ and 15 female $(31.3 \pm 6.7$ years, $162.9 \pm 3.9$ $\mathrm{cm}$, and $56.0 \pm 5.3 \mathrm{~kg}$ ) recreationally-trained endurance runners were recruited. Maximal oxygen uptake, running economy, conventional (concentric flexors-to-concentric extensors) and functional (concentric flexors-to-eccentric extensors) hip isokinetic strength balance ratios, peak torque of the hip flexor and extensor muscles, total body mass, and fat-free mass were measured. Running economy was assessed on two separate days by means of the energy running cost $\left(E_{c}\right)$ using a motorized treadmill at 10.0 and $12.0 \mathrm{~km} . \mathrm{h}^{-1}$ (3\% gradient) and 11.0 and $14.0 \mathrm{~km} \cdot \mathrm{h}^{-1}$ ( $1 \%$ gradient). Results. The functional balance ratio was significantly and negatively associated with $E_{c}$ at $11.0(r=-0.43, P=0.04)$ and $12.0 \mathrm{~km} \cdot \mathrm{h}^{-1}(r=-0.65, P=0.04)$ when using a $3 \%$ gradient in male runners. Considering muscular strength, male runners only showed a significant relationship between $E_{c}$ 
(assessed at $12 \mathrm{~km} \cdot \mathrm{h}^{-1}$ and a 3\% gradient) and peak torque for extensor muscle eccentric action ( $r=0.72, P=0.04$ ). For female runners, only peak torque relative to total body mass for extensor muscles $\left(180^{\circ} . s^{-1}\right)$ was positively associated with $E_{c}$ when assessed at $10 \mathrm{~km} \cdot \mathrm{h}^{-1}$ using a $3 \%$ gradient $(r=0.59, P=0.03)$. No significant relationships were found between $E_{c}$ and total body mass or fat free mass. Discussion. Given that the functional balance ratio was associated with a better $E_{c}$, coaches and athletes should consider implementing a specific strengthening program for hip flexor muscles to increase the functional ratio. 
3 Hip muscular strength balance is associated with running economy in recreationally-

4 trained endurance runners

5

Short title: Running economy in trained runners

6

7

Wallace de Almeida Silva ${ }^{1}$, Claudio Andre Barbosa de Lira ${ }^{2}$, Rodrigo Luiz Vancini ${ }^{3}$,

8 Marilia Santos Andrade ${ }^{1}$

9

$10{ }^{1}$ Departamento de Fisiologia, Universidade Federal de São Paulo, São Paulo, São Paulo, Brazil.

$11{ }^{2}$ Setor de Fisiologia Humana e do Exercício, Laboratório de Avaliação do Movimento Humano,

12 Universidade Federal de Goiás, Goiânia, Goiás, Brazil.

$13{ }^{3}$ Centro de Educação Física e Desportos, Universidade Federal do Espírito Santo, Vitória, Espírito 14 Santo, Brazil.

15

16 Corresponding author:

17 Claudio de Lira

18 E-mail: andre.claudio@gmail.com

19 


\section{ABSTRACT}

22 Background. The percentage of sustained maximal oxygen uptake and the running economy are

23 important factors that determine the running success of endurance athletes. Running economy is

24 defined as the oxygen uptake required to run at a given speed and depends on metabolic,

25 cardiorespiratory, biomechanical, neuromuscular, and anthropometric factors. With regards to

26 anthropometric characteristics, total body mass seems to be a crucial factor for the running

27 economy. Moreover, neuromuscular components, especially knee muscular strength and the

28 strength balance ratio, also seem to be critical for the running economy. In addition to knee muscle

29 strength, hip muscle strength is also an important contributor to running performance on level or

30 hilly ground. However, the relationship between running economy and the hip muscles is

31 unknown. Thus the aim of the present study was to verify whether hip flexor and extensor

32 isokinetic peak torque, the isokinetic strength balance ratio, total body mass and fat free mass were

33 associated with running economy in both sexes and to compare sex differences in physical fitness

34 and isokinetic strength characteristics.

35 Methods. A total of 24 male $(31.0 \pm 7.7$ years, $176.2 \pm 7.3 \mathrm{~cm}$, and $70.4 \pm 8.4 \mathrm{~kg})$ and 15 female

$36(31.3 \pm 6.7$ years, $162.9 \pm 3.9 \mathrm{~cm}$, and $56.0 \pm 5.3 \mathrm{~kg})$ recreationally-trained endurance runners were

37 recruited. Maximal oxygen uptake, running economy, conventional (concentric flexors-to-

38 concentric extensors) and functional (concentric flexors-to-eccentric extensors) hip isokinetic

39 strength balance ratios, peak torque of the hip flexor and extensor muscles, total body mass, and

40 fat-free mass were measured. Running economy was assessed on two separate days by means of 
41 the energy running cost $\left(\mathrm{E}_{\mathrm{c}}\right)$ using a motorized treadmill at 10.0 and $12.0 \mathrm{~km} \cdot \mathrm{h}^{-1}(3 \%$ gradient $)$

42 and 11.0 and $14.0 \mathrm{~km} \cdot \mathrm{h}^{-1}(1 \%$ gradient $)$.

43 Results. The functional balance ratio was significantly and negatively associated with $\mathrm{E}_{\mathrm{c}}$ at 11.0

$44(\mathrm{r}=-0.43, P=0.04)$ and $12.0 \mathrm{~km} \cdot \mathrm{h}^{-1}(\mathrm{r}=-0.65, P=0.04)$ when using a $3 \%$ gradient in male

45 runners. Considering muscular strength, male runners only showed a significant relationship

46 between $\mathrm{E}_{\mathrm{c}}$ (assessed at $12 \mathrm{~km} \cdot \mathrm{h}^{-1}$ and a $3 \%$ gradient) and peak torque for extensor muscle

47 eccentric action $(\mathrm{r}=0.72, P=0.04)$. For female runners, only peak torque relative to total body

48 mass for extensor muscles $\left(180^{\circ} \cdot \mathrm{s}^{-1}\right)$ was positively associated with $\mathrm{E}_{\mathrm{c}}$ when assessed at 10

$49 \mathrm{~km} \cdot \mathrm{h}^{-1}$ using a 3\% gradient $(\mathrm{r}=0.59, P=0.03)$. No significant relationships were found between

$50 \quad \mathrm{E}_{\mathrm{c}}$ and total body mass or fat free mass.

51 Discussion. Given that the functional balance ratio was associated with a better $\mathrm{E}_{\mathrm{c}}$, coaches and

52 athletes should consider implementing a specific strengthening program for hip flexor muscles to

53 increase the functional ratio.

54

55

56

57

58

59

60

\section{INTRODUCTION}


62 The maximum oxygen-uptake ability, the percentage of sustained maximal oxygen uptake

$63\left(\rrbracket^{\sharp} \mathrm{O}_{2}\right.$ max), and the running economy are important factors that determine running success in

64 endurance athletes (Basset \& Howley, 2000). In addition, while $\mathbb{}^{\mathrm{H}} \mathrm{O}_{2}$ max represents the maximal

65 rate of oxygen uptake, the $\% \mathbb{}^{\sharp} \mathrm{O}_{2}$ max represents the fraction of $\|^{\sharp} \mathrm{O}_{2}$ that a runner can maintain

66 during a running event. Running economy is the metabolic cost required to cover a given distance

67 (Shaw et al., 2014). In this sense, runners with a good running economy experience lower

68 metabolic costs than runners with a poor running economy at the same absolute intensity (Thomas,

69 Fernhall \& Granat, 1999).

70 In a $10-\mathrm{km}$ race, almost $65 \%$ of the performance variance between runners with a similar

$71 \rrbracket_{2} O_{2}$ max can be explained by running economy, which is measured by $\Downarrow_{2} O_{2}\left(\mathrm{ml} \cdot \mathrm{kg}^{-1} \cdot \mathrm{min}^{-1}\right)$ at a

72 common treadmill speed (Conley \& Krahenbuhl, 1980). Furthermore, running economy depends

73 on metabolic, cardiorespiratory, biomechanical, neuromuscular, and anthropometric factors

74 (Santos-Concejero et al., 2014). With regards to the anthropometric characteristics, body

75 composition (fat mass and fat free mass) seems to be a crucial factor. Several studies have

76 identified associations between anthropometric variables and running economy (Kong \& Heer,

77 2008; Dellagrana et al., 2015; Hoogkamer, Kram \& Arellano, 2017); for example, Vernillo et al.

78 (2013) studied Kenyan marathon runners and concluded that a minimal body fat percentage was

79 desirable, as a higher fat mass correlated with a worse running economy. In addition, total body

80 mass also seems to be important for running performance. Marc et al. (2014) studied

81 anthropometric data from the world's top 100 marathon runners between 1990 and 2011 and

82 showed that runners got lighter over the years. In 1990, men weighed an average of $59.6 \pm 2.30$

$83 \mathrm{~kg}$, while in 2011 , they weighed $56.2 \pm 1.10 \mathrm{~kg}$. Kenyan athletes also have smaller calf

84 circumferences than boys from other continents (Larsen, 2003), which indicates that although 
85 muscle mass is primarily responsible for energy use, a reduced muscle mass may be associated

86 with good running economy if there is sufficient muscle mass to provide the required force and

87 support the metabolic rate (Fletcher \& MacIntosh, 2017). In this manner, the running economy is

88 estimated to worsen when the leg mass increases by $1 \mathrm{~kg}$; however, if the $1 \mathrm{~kg}$ increase occurs in

89 the trunk and not the lower limbs, the worsening running economy is less evident (Jones et al.

90 1986).

91 Muscular strength and endurance also seem to be critical components for the running

92 economy. The endurance of knee flexor and extensor muscles was negatively associated with

93 running economy when assessed by $\rrbracket^{\sharp} \mathrm{O}_{2}$ using a fixed treadmill speed (Westblad, Svedenhag \&

94 Rolf, 1996; Hayes et al., 2011). Furthermore, there is also evidence to suggest that strength training

95 is able to improve running economy (Fletcher, Esau \& Macintosh, 2009; Balsalobre-Fernández,

96 Santos-Concejero \& Grivas, 2016; Blagrove, Howatson \& Hayes, 2017).

97 Apart from the importance of muscular strength, the strength balance ratio between agonist

98 and antagonist muscles, which is considered as an index of joint stability, also seems to be of

99 fundamental importance. Two different strength balance ratios have been studied: 1) conventional

100 balance ratio, which is assessed by the concentric peak torque of antagonist muscles divided by

101 the concentric peak torque of agonist muscles and is associated with static joint stability; and 2)

102 functional balance ratio, which is assessed by the eccentric peak torque of antagonist muscles

103 divided by the concentric peak torque of agonist muscles and is associated with dynamic joint

104 stability. Sundby \& Gorelick (2014) demonstrated that a higher functional balance ratio of the knee

105 joint was associated with a better running economy, and this association was even better than with

106 absolute thigh muscular strength. Higher functional balance ratio values may result in less energy

107 expenditure during running; however, this relationship has been poorly studied for the hip muscles. 
109 power generation during the swing and stance phase; however, hip flexor and extensor muscles

110 also contribute significantly to the generation of running power (Novacheck, 1998). For example,

111 hip extensor muscles are mainly involved in power generation during the second half of swing,

112 while hip flexor muscles are mainly involved after toe off (Novacheck, 1998). Therefore the

113 strength of these muscles also contribute to stride length (Novacheck, 1998), which is significantly

114 related to running economy (Folland et al., 2017).

115 Although hip muscle strength is considered to be of fundamental importance to runners,

116 studies regarding the relationship between the hip strength ratio and running economy are scarce.

117 Another interesting point from the running economy literature is that the vast majority of studies

118 only consider level-ground running. Therefore little is known about uphill races, which have

119 become increasingly popular in the last 40 years and seen exponential participation growth

120 (Hoffman, Ong \& Wang, 2010).

121 During uphill running, the speed decreases by $0.1-0.3 \mathrm{~km} \cdot \mathrm{h}^{-1}$ for each $1 \%$ increase in

122 gradient (Townshend, Worringham \& Stewart, 2010), which leads to important biomechanical,

123 neuromuscular, and physiological adaptations. Moreover, uphill running is characterized by a

124 shorter swing phase and a greater proportion of the stride cycle spent in the stance position

125 (Swanson \& Caldwell, 2000). The lower limb muscles also perform higher net mechanical work

126 compared to level running. The increased work demands caused by the hills are met by an

127 increased power output from all joints, particularly the hip (Vernillo et al., 2017). Since the hip

128 muscles are significantly involved in hill running, the muscle strength balance between them may

129 also be important for running economy. Therefore it was hypothesized that higher hip muscular

130 strength ratio values imply lower energy expenditure (i.e., a better running economy). 
131 Running economy was typically measured as the oxygen cost of running, which is defined

132 as the oxygen required to cover a given distance (Foster and Lucia, 2007; Ingham et al., 2008; Tam

133 et al., 2012) or maintain a given speed (Saunders et al., 2004). This measurement assumes that the

134 oxygen cost is an index of adenosine triphosphate turnover during submaximal exercise and thus

135 reflects the metabolic cost of running. However, more recent studies have questioned the adequacy

136 of this representation, as the same $\rrbracket^{\sharp} \mathrm{O}_{2}$ could reflect different derived energy depending on the

137 substrate (carbohydrate or fat) used (Fletcher, Esau \& Macintosh, 2009; Shaw et al., 2014).

138 Therefore this study calculated running economy by considering the substrate used, which is likely

139 to provide a more valid (Fletcher, Esau \& Macintosh, 2009) and reliable (Blagrove, Howatson \&

140 Hayes, 2017) measurement. It was also measured as the energy cost of running, as previous studies

141 recommended this as the primary measurement of running economy (Shaw et al., 2014, 2015).

142 Moreover, as previous work indicated that the relationship between body mass and oxygen uptake

143 did not increase proportionately (Lundstrom et al., 2017), body mass was scaled allometrically and

144 energy running cost $\left(\mathrm{E}_{\mathrm{c}}\right)$ was expressed in $\mathrm{kcal} \cdot \mathrm{kg}^{-0.75} \cdot \mathrm{km}^{-1}$.

145 Although a positive relationship does not indicate a cause and effect relationship, the

146 knowledge of a possible association between the hip strength balance ratio and running economy

147 may contribute to a training scheme and therefore lead to improved performance. To the best of

148 the author's knowledge, this is the first study to investigate the association between hip strength

149 balance and $\mathrm{E}_{\mathrm{c}}$ (and running economy). Therefore the purpose of this study was to verify whether

150 the hip strength balance ratio, hip muscular strength, total body mass and fat free mass were

151 associated with $E_{c}$ during flat-floor or uphill running in recreationally-trained endurance runners.

152 Moreover, the study also aimed to compare sex differences in physical fitness and isokinetic

153 strength characteristics. 


\section{MATERIALS \& METHODS}

156 Study design

157 The physical assessments were divided across 3 days and were separated by 1 week

158 between each visit. The participants continued their regular training program but were asked to

159 refrain from strenuous workouts on the day before each test. The variables evaluated during visit

160 one included $\mathbb{H}_{2}$ max , the ventilatory threshold (VT), the respiratory compensation point (RCP),

161 height, body mass, fat-free mass, and fat mass. During visit two, running economy was evaluated

162 on a motorized treadmill using two running intensities for level-ground (11 and $14 \mathrm{~km} \cdot \mathrm{h}^{-1}$ at a $1 \%$

163 gradient) and two for uphill running (10 and $12 \mathrm{~km} \cdot \mathrm{h}^{-1}$ at a $3 \%$ gradient). During visit three, hip

164 flexor and extensor muscle peak torque were evaluated at 60 and $180^{\circ} \cdot \mathrm{s}^{-1}$.

165 Subjects

166 A total of 39 recreationally-trained endurance runners (24 male and 15 female) participated

167 in the study. Male subjects were aged $31.0 \pm 7.7$ years, were $176.2 \pm 7.3 \mathrm{~cm}$ tall, and weighed 70.4

$168 \pm 8.4 \mathrm{~kg}$. Female subjects were aged $31.3 \pm 6.7$ years, were $162.9 \pm 3.9 \mathrm{~cm}$ tall, and weighed 56.0

$169 \pm 5.3 \mathrm{~kg}$. Male and female athletes trained $5.0 \pm 1.9$ and $4.1 \pm 1.8$ days $/$ week, respectively, and the

170 training volume was $68.2 \pm 39.8$ and $48.5 \pm 28.6 \mathrm{~km} /$ week for male and female runners,

171 respectively. None of the runners were involved in any other sports. All participants were informed

172 of the intent and procedures of the study and signed an informed consent form before data

173 collection. The study protocol was approved by the Human Research Ethics Committee of the 
174 Federal University of São Paulo and conformed to the principles outlined in the Declaration of

175 Helsinki (CAAE: 50127315.3.0000.5505, UNIFESP, São Paulo, SP, Brazil).

176 All participants answered the Physical Activity Readiness Questionnaire (PAR-Q) before

177 testing. The inclusion criteria were responding "no" to all PAR-Q questions, being involved in

178 long-distance running for at least 1 year, training at least four times per week, participating in

179 running events spontaneously, and being able to complete a 10-km race in 45 (men) or 50 (women)

$180 \mathrm{~min}$.

181 The exclusion criteria included suffering from pain or undergoing surgery on the lower

182 limbs within the last 6 months; presenting metabolic, cardiovascular, neurologic, or endocrine

183 diseases; using medical drugs or any performance-altering substances; or an inability to perform

184 physical activity.

185 Procedures

186 Anthropometric evaluation

187 Total body mass $(\mathrm{kg})$, fat-free mass $(\%$ and $\mathrm{kg})$, and fat mass $(\mathrm{kg})$ were evaluated using

188 dual-energy X-ray absorptiometry (DPX NT, GE Healthcare, USA). This method was previously

189 shown to be reliable and valid (Colyer et al., 2016). Body mass and height were also measured.

190 Cardiopulmonary exercise test (CPET)

191 Maximum incremental treadmill tests on a motorized treadmill (Inbrasport, ATL, Brazil)

192 were performed using a computer-based exercise system (Quark, Cosmed, Italy) with breath-by-

193 breath analysis of ventilatory and metabolic variables. The subjects were instructed to refrain from 
194 eating $2 \mathrm{~h}$ before the CPET. The gas analyzer was calibrated using gas of a known concentration

$195\left(16 \% \mathrm{O}_{2}\right.$ and $4 \% \mathrm{CO}_{2}$; White Martins, Rio de Janeiro, Brazil $)$ and ambient air. The flow meter was

196 calibrated using a 3 L syringe (Hans Rudolph, Inc, Shawnee, KS, USA). All participants were

197 subjected to a 3-min warm-up period at a comfortable running speed, which they selected

198 individually.

199 The running intensity was increased by $1 \mathrm{~km} \cdot \mathrm{h}^{-1}$ every minute until the subject reached

200 voluntary exhaustion. At the cessation of exercise, participants were asked to rate their dyspnea

201 using the Borg scale (Borg, 1982). The initial CPET speed was selected according to the runner's

202 aerobic conditioning $\left(8\right.$ or $9 \mathrm{~km} \cdot \mathrm{h}^{-1}$ ) to guarantee that the total CPET time was between 8 and 12

$203 \min$ (Buchfuhrer et al., 1983). This is long enough to provide useful physiological information

204 yet not long enough to burden the patient and staff.

205 Participants were verbally encouraged to exercise for as long as possible during the CPET.

206 All measured data were fitted as the mean of 20 s. ${ }^{\sharp} \mathrm{O}_{2}$ max was always defined as the highest

20720 -s average $\mathbb{}^{\natural} \mathrm{O}_{2}$ value, with the inclusion criteria consistent with conventional guidelines for

$208 \sqrt{\mathrm{O}_{2}}$ max [e.g., an inability to sustain the workload, relative heart rate (HR) at maximal exercise

$209>95 \%$ age-predicted HR, respiratory exchange rate at maximal exercise $>1.1$, and $\Downarrow^{\natural} O_{2}$ plateau

210 (the point at which ${ }^{\natural} O_{2}$ increases $<150 \mathrm{~mL} \cdot \mathrm{min}^{-1}$ for a given increase in workload)] (Howley,

211 2007).

212 The VT was determined based on an inflection in the ventilation curve, an increase in the

213 ventilatory equivalent for oxygen without an increase in the ventilatory equivalent for carbon

214 dioxide, and an increase in the partial pressure of exhaled oxygen. RCP was determined based on

215 an inflection in the ventilation curve, an increase in the ventilatory equivalent for oxygen and the 
216 ventilatory equivalent for carbon dioxide, and a decrease in the partial pressure of exhaled carbon

217 dioxide (Whipp, Ward \& Wasserman, 1986). The treadmill speed associated with the occurrence

218 of the VT was used as a reference for the individual's maximal moderate exercise capacity. A

219 Suunto Electronics HR monitor (Ambit 2s, Suunto, Finland) was used to record HR in real time.

220 Running economy test

221 Subjects were instructed to arrive at the laboratory in a hydrated state at least $2 \mathrm{~h}$

222 postprandial and to avoid strenuous exercise for $24 \mathrm{~h}$ before the test. Running economy evaluation

223 was performed with the same gas analyzer used during the CPET. The test was preceded by a 10-

224 min warm-up period at a comfortable speed of the participant's choice. In the first test, the running

225 speed was set to $11 \mathrm{~km} \cdot \mathrm{h}^{-1}$ (1\% gradient) to simulate level-ground running with air resistance

226 (Jones \& Doust, 1996). In the second test, the running speed was set to $10 \mathrm{~km} \cdot \mathrm{h}^{-1}$ (3\% gradient)

227 to simulate uphill running. The test speeds were lower than the VT for all participants, which was

228 confirmed by $\Downarrow_{O_{2}}$ stabilization during the last $2 \mathrm{~min}$. The criterion used to identify $\mathbb{}_{2} \mathrm{O}_{2}$

229 stabilization is an increase $\leq 150 \mathrm{ml} / \mathrm{min}$ during the last 2 minutes of the test. Each running

230 economy test lasted for $4 \mathrm{~min}$, and subjects had a 5 -min rest period (standing fully connected to

231 the metabolic cart) between the two test velocities. In the third test, the running speed was set at

$23214 \mathrm{~km} \cdot \mathrm{h}^{-1}$ (1\% gradient), and in the fourth test, the running speed was set at $12 \mathrm{~km} \cdot \mathrm{h}^{-1}$ (3\%

233 gradient) to simulate uphill running. Only participants who presented a VT $>14 \mathrm{~km} \cdot \mathrm{h}^{-1}$ participated

234 in the third and fourth tests.

235 Running economy was assessed by means of $E_{c}$. For each speed, breath-by-breath

236 measurements were averaged every $10 \mathrm{~s}$ during the final minute of each submaximal stage, and

$237 \sqrt{ } \mathrm{O}_{2}$ and $\mathbb{\natural}^{\mathrm{C}} \mathrm{CO}_{2}$ were averaged to determine the $\mathrm{E}_{\mathrm{c}}$ (Fletcher, Esau \& Macintosh, 2009). The 
238 nonprotein respiratory quotient equations (Péronnet \& Massicotte, 1991) were used to estimate the

239 percentage of fat utilization, and the energy supplied by each substrate was calculated by

240 multiplying the use of fat and carbohydrate by 9.75 and $4.07 \mathrm{kcal}$, respectively. The $\mathrm{E}_{\mathrm{c}}$ of running

241 was chosen to evaluate running economy as it is likely to provide a more valid (Fletcher, Esau \&

242 Macintosh, 2009) and reliable (Blagrove, Howatson \& Hayes, 2017) measurement compared to

243 oxygen cost. It is common to report $\mathrm{E}_{\mathrm{c}}$ per $\mathrm{kg}$ of body mass (Shaw, Ingham \& Folland, 2018);

244 however, the relationship between body mass and oxygen uptake does not increase proportionately

245 and therefore body mass should be scaled allometrically. As in a previous study, body mass was

246 raised to the power of $0.75\left(\mathrm{kcal}^{\mathrm{kg}}{ }^{-0.75} \cdot \mathrm{km}^{-1}\right)$ (Lundstrom et al., 2017).

\section{Isokinetic strength test}

248 The hip strength test was performed on an isokinetic dynamometer (Biodex Medical

249 System, Shirley, NY, USA). A calibration process was conducted on the equipment according to

250 the user manual, which included gravity correction of the lower limb weight. All participants

251 performed an initial 4-min warm-up on a motorized treadmill $\left(10-11 \mathrm{~km} \cdot \mathrm{h}^{-1}\right)$. Stretching exercises

252 were avoided as these could influence the strength results (Mascarin et al., 2015). Before the test,

253 runners had their trunk and hip stabilized with Velcro straps. According to the manufacturer's

254 specifications, the hip was assessed with the subject lying in a supine position with the seat fully

255 reclined and the knees flexed at $90^{\circ}$ (relative to full extension). The hip's axis (greater trochanter

256 used as a bony landmark) stayed in neutral extension (lower limb stayed in a horizontal plane

257 parallel to the ground) and was then aligned with the dynamometer's shaft (Figure 1). The limb

258 not being tested was held in a knee-flexed and hip-extended position on the table. Hip attachment

259 to the dynamometer was adjusted on the thigh near the knee. The range-of-motion limitations were 
260 set beginning from the hip neutrally extended on the table to the hip being maximally flexed. The

261 dynamometer orientation was selected at $0^{\circ}$ (relative to the horizontal plane and parallel to the

262 ground).

263

*** Figure 1 near here $* * *$

264 Concentric hip strength was evaluated during five cycles of maximal flexion and extension

265 at 60 and $180^{\circ} \cdot \mathrm{s}^{-1}$ (Julia et al., 2010), while eccentric evaluation was performed during three cycles

266 at $180^{\circ} \cdot \mathrm{s}^{-1}$ (Zapparoli \& Riberto, 2017). The force-velocity relationship was hyperbolic, and a

267 slow test speed $\left(60^{\circ} / \mathrm{s}\right)$ was chosen to evaluate the maximum strength values. On the other hand,

268 functional movements occur at faster angular speeds, therefore a faster test speed $\left(180^{\circ} / \mathrm{s}\right)$ was also

269 chosen. Volunteers cannot develop torque at higher angular speeds, therefore the angular speed of

$270180^{\circ} / \mathrm{s}$ was the maximum speed used. Prior to the test, all volunteers performed two submaximal

271 contractions to familiarize themselves with the angular speed of the test. Joint evaluation was

272 performed in the dominant lower limb, which was determined by asking the participant which limb

273 they preferred to use to kick a ball. For the purposes of standardization and participant safety, the

274 test started by concentric action (as this was easier to perform) and was followed by eccentric

275 contraction. Peak torque of the hip flexor and extensor muscles were measured, and the

276 conventional strength balance ratio (concentric peak torque of flexor/extensor muscles) and

277 functional strength balance ratio (eccentric peak torque of flexor/concentric peak torque of

278 extensor muscles) were calculated.

279 Statistical analysis

280 All statistical analyses were performed using Statistica software (version 6.0). All data

281 were normally distributed with equal variances (established by the Kolmogorov-Smirnov test), 
282 therefore parametric tests were used. Student's t-tests for independent variables were used to

283 compare sex differences relative to anthropometric, CPET, $\mathrm{E}_{\mathrm{c}}$, isokinetic testing, and physical

284 training data. Pearson's correlation coefficients were calculated between isokinetic strength

285 variables and $\mathrm{E}_{\mathrm{c}}$. Data were expressed as mean \pm standard deviation, and the level of significance

286 was set at 0.05 .

287

288 RESULTS

289 The participant characteristics are presented in Table 1. Female runners had a significantly

290 higher fat mass percentage than male runners (Table1). In addition, male runners had significantly

291 higher fat-free mass $(\mathrm{kg})$ and $\Downarrow^{\natural} O_{2}$ max levels (Table 1).

292

*** Table 1 near here $* * *$

293 The $\mathrm{E}_{\mathrm{c}}$ for female runners was not different from male runners when assessed at $10 \mathrm{~km} \cdot \mathrm{h}^{-1}$

294 during uphill running or $11 \mathrm{~km} \cdot \mathrm{h}^{-1}$ during level-ground running. At the other test speeds $\left(12 \mathrm{~km} \cdot \mathrm{h}^{-1}\right.$

295 uphill and $14 \mathrm{~km} \cdot \mathrm{h}^{-1}$ flat), the sample was composed only of male runners $(\mathrm{n}=9)$ with a VT $>14$

$296 \mathrm{~km} \cdot \mathrm{h}^{-1}\left(\mathrm{VT}=14.2 \pm 0.4 \mathrm{~km} \cdot \mathrm{h}^{-1}\right)$.

297 The weekly frequency of training and training volume was not different between the sexes.

298 Hip muscle absolute or relative to total body mass peak torque values in both concentric and

299 eccentric action were higher in male than female runners. The conventional balance ratio was also

300 higher in male runners, but the functional balance ratio was not different between the sexes (Table

$3012)$.

***Table 2 near here ${ }^{* * *}$ 
303 Regarding the associations between $\mathrm{E}_{\mathrm{c}}$ and the strength balance ratios (male runners),

304 correlation coefficients ranged from 0.01 to 0.29 and -0.72 to 0.09 for the conventional balance

305 ratio and functional balance ratio, respectively (Table 3). The functional balance ratio was

306 significantly and negatively associated with $\mathrm{E}_{\mathrm{c}}$ when assessed at $11 \mathrm{~km} \cdot \mathrm{h}^{-1}$ using a $1 \%$ gradient $(\mathrm{r}$ $307=-0.43, P=0.04)$ and at $12 \mathrm{~km} \cdot \mathrm{h}^{-1}$ using a $3 \%$ gradient $(\mathrm{r}=-0.72, P=0.04)$ in male runners

308 (Table 3). For female runners, the associations between $E_{c}$ and the conventional and functional 309 balance ratio ranged from -0.16 to 0.35 ; however, neither of these associations were significant 310 (Table 4).

311 Absolute strength values seemed to be unrelated to $E_{c}$ in both sexes. For male runners, only

312 peak torque for extensor muscles in eccentric action was positively associated with $E_{c}$ when

313 assessed at $12 \mathrm{~km} \cdot \mathrm{h}^{-1}$ using a $3 \%$ gradient $(\mathrm{r}=0.72, P=0.04)$. For female runners, only peak 314 torque relative to total body mass for extensor muscles $\left(180^{\circ} \cdot \mathrm{s}^{-1}\right)$ in concentric action was

315 positively associated with Ec when assessed at $10 \mathrm{~km} \cdot \mathrm{h}^{-1}$ using a $3 \%$ gradient $(\mathrm{r}=0.59, P=0.03)$.

316 Finally, total body mass and fat free mass were not significantly associated with $E_{c}$ in either the 317 male (Table 3) or female (Table 4) runners.

***Table 4 near here $* * *$

320

\section{DISCUSSION}

322 The primary aim of this study was to verify the relationships of isokinetic hip strength, 323 muscular strength balance ratios, total body mass and fat free mass with $\mathrm{E}_{\mathrm{c}}$. The main outcome 
324 was that the hip functional balance ratio was strongly associated with $\mathrm{E}_{\mathrm{c}}$ at $11(1 \%$ gradient $)$ and

$32512 \mathrm{~km} \cdot \mathrm{h}^{-1}$ (at $3 \%$ gradient) in male runners. This indicates that a higher functional balance ratio is

326 associated with better running economy.

327 The conventional and functional balance ratios reflect the joint stability, therefore it was

328 hypothesized that the higher the ratio, the lower the ${ }^{\natural} O_{2}$ during running, as the runner would not

329 expend energy for joint stability. Sundby \& Gorelick (2014) recently aimed to verify the

330 association between running economy and knee stability during running; however, they only

331 studied $\mathrm{E}_{\mathrm{c}}$ using a level gradient and only assessed the knee joint in females. The authors found a

332 negative and significant association between the functional balance ratio and running economy,

333 therefore they concluded that runners should consider implementing hamstring exercises to

334 improve their functional balance ratios.

335 The results from this study showed that the conventional balance ratio was not associated with Ec

336 in either male or female runners. Conversely, the functional balance ratio was significantly and

337 negatively associated with $\mathrm{E}_{\mathrm{c}}$ when tested at $11 \mathrm{~km} \cdot \mathrm{h}^{-1}$ using a $1 \%$ gradient or $12 \mathrm{~km} \cdot \mathrm{h}^{-1}$ using a

$3383 \%$ gradient in male runners. Running speed is a relevant factor in the maintenance of a stable gait,

339 and muscular balance is a great contributor to stability during running (Sasaki \& Neptune, 2006).

340 Therefore, these data suggest that runners with a higher functional balance ratio between the hip

341 muscles may have a steady and fast running style at submaximal speeds, thus generating less

342 energy cost. However, caution should be taken because when two variables are found to

343 be correlated, it not necessarily shows that one variable causes the other. It is considered

344 a questionable cause logical fallacy when two events occurring together are taken to have

345 established a cause-and-effect relationship. Therefore, the significant and negative relationship 
346 between Ec and functional balance ratio, not necessary indicates a cause-and -effect relationship

347 between these two variables.

$348 \quad$ Sundby \& Gorelick (2014) studied seven well-trained female runners and 11 recreational

349 female runners and identified a significant relationship between knee joint functional balance ratio

350 and $E_{c}$ in both groups, thus suggesting that knee muscular strength balance may be important for

351 running economy.

352 A running task is a sequence of concentric and eccentric work, thus the elastic energy

353 provided by the stretching muscle is used in the subsequent concentric muscle action and results

354 in increased strength production with reduced energy expenditure (Spurrs, Murphy \& Watsford,

355 2003). This may help explain the significant relationship between the higher functional balance

356 ratio and $\mathrm{E}_{\mathrm{c}}$ that was identified in this study, at least for men. Complementing this data, Farley et

357 al. (1991) explained that the metabolic rate increases at lower speeds as the body does not behave

358 in an optimal spring-like manner and the elastic energy is dissipated as heat. This may provide an 359 explanation for why the functional balance ratio and $\mathrm{E}_{\mathrm{c}}$ association was higher at faster running 360 speeds.

361 On the other hand, absolute and relative peak torque values for hip flexor and extensor 362 muscles presented almost any relationship with $\mathrm{E}_{\mathrm{c}}$. Of the 40 strength variables analyzed in the 363 male and female runners, only one was related to $E_{c}$. Sundby \& Gorelick (2014) analyzed the 364 relationship between knee flexor and extensor peak torque values and running economy in female

365 runners and obtained similar results. They also found no relationship between muscular strength 366 (absolute or relative to body mass values) and running economy. 
367 Previous studies reported the importance of total body mass in runners (Joyner, Ruiz \&

368 Lucia, 2011). Hoogkamer, Kram \& Arellano (2017) stated that approximately $74 \%$ of the

369 metabolic cost of running was used to support body mass. They also argued that a reduction in

370 body mass was a good strategy to improve $\mathrm{E}_{\mathrm{c}}$. The results from this study showed that total body

371 mass was not associated with $\mathrm{E}_{\mathrm{c}}$ in either male or female runners. These results were expected, as

$372 \mathrm{E}_{\mathrm{c}}$ was expressed relative to total body mass and therefore the body mass effect on running

373 economy was abolished.

374 In the same way, the percentage of fat-free mass and absolute values were not related to

$375 E_{c}$. Although several studies report improved $E_{c}$ resulting from strength training (Balsalobre-

376 Fernández, Santos-Concejero \& Grivas, 2016; Beattie et al., 2017), caution should be taken with

377 traditional physical training programs, as hip muscle strength values were not related to $\mathrm{E}_{\mathrm{c}}$.

378 Moreover, such a method could cause a hypertrophic effect, which may negatively affect $E_{c}$

379 (Beattie et al., 2017).

380

381 Study limitation

382 A number of limitations of the study must be mentioned. First, this study was cross-

383 sectional and we were therefore unable to assess the responsiveness of training over time in

384 analyzed variables. Therefore, future studies should employ a longer period using a longitudinal

385 design. Second, the cross-sectional data made difficult to assess the direction of causality.

386 Nevertheless, we believe that these limitations do not prevent conclusions being drawn from the

387 study.

388 


\section{CONCLUSION}

$390 \quad$ Highly-trained male and female runners were not different in terms of their running

391 economy. Moreover, the results showed that higher the functional balance ratio is associated

392 with lower the $\mathrm{E}_{\mathrm{c}}$. However, absolute values for muscular strength were not related to the

393 running energy cost. Therefore running economy may be related to greater hip flexor muscle

394 strength relative to extensor muscle strength and not to absolute muscle strength.

395

396

PRACTICAL APPLICATIONS

397

Considering that the functional balance ratio was significantly and negatively associated

398 with $E_{c}$, coaches and athletes should consider implementing hip flexor muscle strengthening

399 exercises to increase the functional balance ratio and improve $\mathrm{E}_{\mathrm{c}}$, besides the significant correlation

400 between these variables does not imply causation.

401

402 FIGURE LEGENDS

403 Figure 1. Positioning assumed by the participant during isokinetic evaluation of the hip.

404

405

406

407

408 REFERENCES 
409 Balsalobre-Fernández C, Santos-Concejero J, Grivas GV. 2016. Effects of strength training on

410 running economy in highly trained runners: A systematic review with meta-analysis of controlled

411 trials. Journal of Strength and Conditioning Research 30:2361-2368 DOI:

$41210.1519 / \mathrm{JSC} .0000000000001316$.

413 Bassett DR Jr, Howley ET. 2000. Limiting factors for maximum oxygen uptake and determinants

414 of endurance performance. Medicine and Science in Sports and Exercise 32:70-84.

415 Beattie K, Carson BP, Lyons M, Rossiter A, Kenny IC. 2017. The effect of strength training on

416 performance indicators in distance runners. Journal of Strength and Conditioning Research 31:9-

41723 DOI: 10.1519/JSC.0000000000001464.

418 Blagrove RC, Howatson G, Hayes PR. 2017. Test-retest reliability of physiological parameters

419 in elite junior distance runners following allometric scaling. European Journal of Sport Science

420 17:1231-1240 DOI: 10.1080/17461391.2017.1364301.

421 Borg GA. 1982. Psychophysical bases of perceived exertion. Medicine and Science in Sports and

422 Exercise 14:377-381.

423 Buchfuhrer MJ, Hansen JE, Robinson TE, Sue DY, Wasserman K, Whipp BJ. 1983.

424 Optimizing the exercise protocol for cardiopulmonary assessment. Journal of Applied

425 Physiology 55:1558-1564.

426 Conley DL, Krahenbuhl GS. 1980. Running economy and distance running performance of

427 highly trained athletes. Medicine and Science in Sports and Exercise 12:357-360.

428 Dellagrana RA, Guglielmo LG, Santos BV, Hernandez SG, da Silva SG, de Campos W. 2015.

429 Physiological, anthropometric, strength, and muscle power characteristics correlates with running 430 performance in young runners. Journal of Strength and Conditioning Research 29:1584-1591 431 DOI: $10.1519 / \mathrm{JSC} .0000000000000784$. 
432 Colyer SL, Roberts SP, Robinson JB, Thompson D, Stokes KA, Bilzon JL, Salo AI. 2016.

433 Detecting meaningful body composition changes in athletes using dual-energy x-ray

434 absorptiometry. Physiological Measurement 37:596-609 DOI: 10.1088/0967-3334/37/4/596.

435 Farley CT, Blickhan R, Saito J, Taylor CR. 1991. Hopping frequency in humans: A test of how

436 springs set stride frequency in bouncing gaits. Journal of Applied Physiology (1985) 71:2127-2132

437 DOI: 10.1152/jappl.1991.71.6.2127.

438 Fletcher JR, Esau SP, Macintosh BR. 2009. Economy of running: beyond the measurement of 439 oxygen uptake. Journal of Appled Physiology 107:1918-1922 DOI: 10.1152/japplphysiol.00307.

440 Fletcher JR, MacIntosh BR. 2017. Running Economy from a Muscle Energetics Perspective.

441 Front Physiol. 22;8:433.

442 Folland JP, Allen SJ, Black MI, Handsaker JC, Forrester SE. 2017. Running technique is an

443 important component of running economy and performance. Medicine and Science in Sports and

444 Exercise 49:1412-1423 DOI: 10.1249/MSS.0000000000001245.

445 Foster C, Lucia A. 2007. Running economy: the forgotten factor in elite performance. Sport

446 Medicine 37:316-319.

447 Hayes PR, French DN, Thomas K. 2011. The effect of muscular endurance on running economy.

448 Journal of Strength and Conditioning Research 25:2464-2469 DOI:

449 10.1519/JSC.0b013e3181fb4284.

450 Hoffman MD, Ong JC, Wang G. 2010. Historical analysis of participation in $161 \mathrm{~km}$ 451 ultramarathons in North America. The International Journal of the History of Sport 27:1877-1891 452 DOI: $10.1080 / 09523367.2010 .494385$. 
453 Hoogkamer W, Kram R, Arellano CJ. 2017. How biomechanical improvements in running

454 economy could break the 2-hour marathon barrier. Sports Medicine 47:1739-1750 DOI:

$45510.1007 / \mathrm{s} 40279-017-0708-0$.

456 Howley ET. 2007. VO2max and the plateau-needed or not? Medicine and Science in Sports and 457 Exercise 39:101-102 DOI: 10.1249/mss.0b013e31802dc897.

458 Ingham SA, Whyte GP, Pedlar C, Bailey DM, Dunman N, Nevill AM. 2008. Determinants of

$459800-\mathrm{m}$ and 1500-m running performance using allometric models. Medicine and Science in

460 Sports and Exercise 40:345-50 DOI: 10.1249/mss.0b013e31815a83dc

461 Jones AM, Doust JH. 1996. A 1\% treadmill grade most accurately reflects the energetic cost of 462 outdoor running. Journal of Sports Sciences 14:321-327 DOI: 10.1080/02640419608727717.

463 Jones BH, Knapik JJ, Daniels WL, Toner MM. 1986. The energy cost of women walking and 464 running in shoes and boots. Ergonomics 29, 439-443.

465 Joyner MJ, Ruiz JR, Lucia A. 2011. The two-hour marathon: who and when? Journal of Applied 466 Physiology 110:275-277 DOI: 10.1152/japplphysiol.00563.2010.

467 Julia M, Dupeyron A, Laffont I, Parisaux JM, Lemoine F, Bousquet PJ, Hérisson C. 2010.

468 Reproducibility of isokinetic peak torque assessments of the hip flexor and extensor muscles.

469 Annals of Physical and Rehabilitation Medicine 53:293-305 DOI: 10.1016/j.rehab.2010.05.002.

470 Kong PW, Heer H. 2008. Anthropometric, gait and strength characteristics of Kenyan distance

471 runners. Journal of Sports Science and Medicine 7:499-504.

472 Larsen HB. 2003. Kenyan dominance in distance running. Comparative Biochemistry and

473 Physiology. Part A, Molecular \& Integrative Physiology 136:161-70 DOI: 10.1016/S1095-

$4746433(03) 00227-7$. 
475 Lundstrom CJ, Biltz GR, Snyder EM, Ingraham SJ. 2017. Allometric scaling of body mass in

476 running economy data: An important consideration in modeling marathon performance. Journal

477 of Human Sport and Exercise 12:267-275. DOI:10.14198/jhse.2017.122.03

478 Marc A, Sedeaud A, Guillaume M, Rizk M, Schipman J, Antero-Jacquemin J, Haida A, 479 Berthelot G, Toussaint JF. 2014. Marathon progress: demography, morphology and 480 environment. Journal of Sports Sciences 32:524-532 DOI: 10.1080/02640414.2013.835436.

481 Mascarin NC, Vancini RL, Lira CA, Andrade MS. 2015. Stretch-induced reductions in

482 throwing performance are attenuated by warm-up before exercise. Journal of Strength and

483 Conditioning Research 29:1393-8 DOI:10.1519/JSC.0000000000000752.

484 Novacheck TF. 1998. The biomechanics of running. Gait and Posture 7:77-95.

485 Péronnet F, Massicotte D. 1991. Table of nonprotein respiratory quotient: an update. Canadian 486 Journal of Sport Sciences 16:23-29.

487 Santos-Concejero J, Tam N, Granados C, Irazusta J, Bidaurrazaga-Letona I, Zabala-Lili J, 488 Gil SM. 2014. Interaction effects of stride angle and strike pattern on running economy. 489 International Journal of Sports Medicine 35:1118-1123 DOI: 10.1055/s-0034-1372640.

490 Sasaki K, Neptune RR. 2006. Muscle mechanical work and elastic energy utilization during 491 walking and running near the preferred gait transition speed. Gait and Posture 23:383-390 DOI: 492 10.1016/j.gaitpost.2005.05.002.

493 Saunders PU, Pyne DB, Telford RD, Hawley JA. 2004. Factors affecting running economy in 494 trained distance runners. Sport Medicine 34:465-485.

495 Shaw AJ, Ingham SA, Folland JP. 2014.

496 The valid measurement of running economy in runners. Medicine and Science in Sports and 497 Exercise 46:1968-73 DOI: 10.1249/MSS.0000000000000311. 
498 Shaw AJ, Ingham SA, Atkinson G, Folland JP. 2015. The correlation between running economy

499 and maximal oxygen uptake: cross-sectional and longitudinal relationships in highly trained

500 distance runners. PLoS One 10:e0123101 DOI: 10.1371/journal.pone.0123101.

501 Shaw AJ, Ingham SA, Folland JP. 2018. The efficacy of downhill running as

502 a method to enhance running economy in trained distance runners. European Journal of Sport

503 Science 21:1-9 DOI: 10.1080/17461391.2018.1449892

504 Spurrs RW, Murphy AJ, Watsford ML. 2003. The effect of plyometric training on distance

505 running performance. European Journal of Applied Physiology 89:1-7 DOI: 10.1007/s00421-002-

506 0741-y.

507 Sundby OH, Gorelick MLS. 2014. Relationship between functional hamstring:quadriceps ratios

508 and running economy in highly trained and recreational female runners. Journal of Strength and

509 Conditioning Research 28:2214-2227 DOI: 10.1519/JSC.0000000000000376.

510 Swanson SC, Caldwell GE. 2000. An integrated biomechanical analysis of high speed incline

511 and level treadmill running. Medicine and Science in Sports and Exercise 32:1146-1155.

512 Tam E, Rossi H, Moia C, Berardelli C, Rosa G, Capelli C, Ferretti G. 2012. Energetics of

513 running in top-level marathon runners from Kenya. European Journal of Applied Physiology

514 112:3797-3806 DOI: 10.1007/s00421-012-2357-1.

515 Thomas DQ, Fernhall B, Granat H. 1999. Changes in running economy during a 5-km run in

516 trained men and women runners. Journal of Strength and Conditioning Research 13:162-167.

517 Townshend AD, Worringham CJ, Stewart IB. 2010. Spontaneous pacing during overground

518 hill running. Medicine and Science in Sports and Exercise 42:160-169 DOI:

519 10.1249/MSS.0b013e3181af21e2. 
520 Vernillo G, Giandolini M, Edwards WB, Morin JB, Samozino P, Horvais N, Millet GY. 2017.

521 Biomechanics and physiology of uphill and downhill running. Sports Medicine 47:615-629 DOI:

$52210.1007 / \mathrm{s} 40279-016-0605-\mathrm{y}$.

523 Vernillo G, Schena F, Berardelli C, Rosa G, Galvani C, Maggioni M, Agnello L, La Torre A.

524 2013. Anthropometric characteristics of top-class Kenyan marathon runners. Journal of Sports

525 Med and Physical Fitness 53:403-408.

526 Westblad P, Svedenhag J, Rolf C. 1996. The validity of isokinetic knee extensor endurance

527 measurements with reference to treadmill running capacities. International Journal of Sports

528 Medicine 17:134-139 DOI: 10.1055/s-2007-972821.

529 Whipp BJ, Ward SA, Wasserman K. 1986. Respiratory markers of the anaerobic threshold.

530 Advances in Cardiology 35:45-64 DOI: 10.1159/000413438.

531 Zapparoli FY, Riberto M. 2017. Isokinetic evaluation of the hip flexor and extensor muscles: A

532 systematic review. Journal of Sport Rehabilitation 26:556-566 DOI: 10.1123/jsr.2016-0036.

533 


\section{Table $\mathbf{1}$ (on next page)}

General characteristics and running economy parameters of male and female runners.

Data are expressed as mean \pm standard deviation. $\mathrm{E}_{\mathrm{c}}$ : energy running cost; $\mathrm{VO}_{2}$ max: maximal oxygen uptake. 
1 Table 1. General characteristics and running economy parameters of male and female runners.

2

3

4

5

6

7

8

9

\begin{tabular}{cccc}
\hline & $\begin{array}{c}\text { Male runners } \\
(\mathbf{n}=\mathbf{2 4})\end{array}$ & $\begin{array}{c}\text { Female runners } \\
(\mathbf{n}=\mathbf{1 5})\end{array}$ & $\boldsymbol{P}$ \\
\hline Variables & & & \\
\hline Fat mass $(\%)$ & $13.5 \pm 6.3$ & $21.8 \pm 3.9$ & $<0.01$
\end{tabular}

Fat-free mass $(\mathrm{kg})$

$57.7 \pm 5.8$

$41.7 \pm 4.0$

$<0.01$

$\sqrt{\mathrm{O}_{2}} \max (\mathrm{mL} / \mathrm{kg} / \mathrm{min})$

$61.3 \pm 6.0$

$54.5 \pm 3.5$

$<0.01$

$10 \mathrm{~km} / \mathrm{h}$ uphill $\mathrm{E}_{\mathrm{c}}$ (kcal. $\mathrm{kg}^{-0.75} \mathrm{~km}^{-1}$ )

$3.7 \pm 0.2$

$3.8 \pm 0.2$

0.15

$11 \mathrm{~km} / \mathrm{h}$ flat-floor $E_{c}$ (kcal.kg ${ }^{-0.75} \mathrm{~km}^{-1}$ )

$3.3 \pm 0.3$

$3.3 \pm 0.2$

0.95

$12 \mathrm{~km} / \mathrm{h}$ uphill $\mathrm{E}_{\mathrm{c}}$ $\left(\mathrm{kcal} . \mathrm{kg}^{-0.75} \cdot \mathrm{km}^{-1}\right)$

$3.5 \pm 0.1$ (men, $\mathrm{n}=9$ )

10

11

$14 \mathrm{~km} / \mathrm{h}$ flat-floor $\mathrm{E}_{\mathrm{c}}$ $\left(\mathrm{kcal} . \mathrm{kg}^{-0.75} \mathrm{~km}^{-1}\right) \quad 3.1 \pm 0.1$ (men, $\mathrm{n}=9$ )

12 Data are expressed as mean \pm standard deviation. $\mathrm{E}_{\mathrm{C}}$ : energy running cost; $\nabla^{\natural} O_{2}$ max : maximal oxygen uptake. 


\section{Table 2 (on next page)}

Peak torque values and conventional and functional balance ratios in the subjects.

Data are expressed as mean \pm standard deviation. ${ }^{*} P<0.05$ compared to male runners. 
1 Table 2. Peak torque values and conventional and functional balance ratios in the subjects.

\begin{tabular}{|c|c|c|c|}
\hline Variables & $\begin{array}{l}\text { Male runners } \\
\qquad(\mathrm{n}=\mathbf{2 4})\end{array}$ & $\begin{array}{l}\text { Female runners } \\
\qquad(\mathbf{n}=\mathbf{1 5})\end{array}$ & $\boldsymbol{P}$ \\
\hline Conventional strength balance ratio & $51.2 \pm 5.1$ & $46.8 \pm 4.3^{*}$ & 0.04 \\
\hline Functional strength balance ratio & $0.30 \pm 0.08$ & $0.30 \pm 0.12$ & 0.84 \\
\hline $\begin{array}{l}\text { Absolute peak torque of extensor muscles at } 60^{\circ} \cdot \mathrm{s}^{-1} \text { in } \\
\text { concentric action }(\mathrm{Nm})\end{array}$ & $205.3 \pm 41.9$ & $138.4 \pm 17.4^{*}$ & $<0.01$ \\
\hline $\begin{array}{l}\text { Peak torque relative to body mass of extensor muscle at } 60^{\circ} . \mathrm{s}^{-1} \\
\text { in concentric action }(\%)\end{array}$ & $292.6 \pm 53.2$ & $247.8 \pm 20.2 *$ & $<0.01$ \\
\hline $\begin{array}{l}\text { Absolute peak torque of flexor muscles at } 60^{\circ} \cdot \mathrm{s}^{-1} \text { in concentric } \\
\qquad \text { action }(\mathrm{Nm})\end{array}$ & $106.9 \pm 19.3$ & $66.3 \pm 10.5^{*}$ & $<0.01$ \\
\hline $\begin{array}{l}\text { Peak torque relative to body mass of flexor muscle at } 60^{\circ} \cdot \mathrm{s}^{-1} \text { in } \\
\text { concentric action }(\%)\end{array}$ & $152.5 \pm 23.6$ & $118.7 \pm 15.2^{*}$ & $<0.01$ \\
\hline $\begin{array}{l}\text { Absolute peak torque of extensor muscles at } 180^{\circ} \cdot \mathrm{s}^{-1} \text { in } \\
\text { concentric action }(\mathrm{Nm})\end{array}$ & $172.7 \pm 39.8$ & $115.1 \pm 13.6^{*}$ & $<0.01$ \\
\hline $\begin{array}{l}\text { Peak torque relative to body mass of extensor muscle at } \\
\qquad 180^{\circ} \cdot \mathrm{s}^{-1} \text { in concentric action (\%) }\end{array}$ & $245.6 \pm 48.6$ & $206.7 \pm 22.4^{*}$ & $<0.01$ \\
\hline $\begin{array}{l}\text { Absolute peak torque of flexor muscles at } 180^{\circ} \cdot \mathrm{s}^{-1} \text { in } \\
\text { concentric action }(\mathrm{Nm})\end{array}$ & $96.0 \pm 14.2$ & $61.9 \pm 9.1^{*}$ & $<0.01$ \\
\hline $\begin{array}{l}\text { Peak torque relative to body mass of flexor muscle at } 180^{\circ} \cdot \mathrm{s}^{-1} \\
\qquad \text { in concentric action }(\%)\end{array}$ & $137.4 \pm 19.2$ & $110.7 \pm 10.2^{*}$ & $<0.01$ \\
\hline Absolute peak torque of extensor muscles at $180^{\circ} . \mathrm{s}^{-1}$ in & $331.6 \pm 77.3$ & $221.8 \pm 51.0^{*}$ & $<0.01$ \\
\hline
\end{tabular}


eccentric action $(\mathrm{Nm})$

Peak torque relative to body mass of extensor muscles at

$$
180^{\circ} . \mathrm{s}^{-1} \text { in eccentric action }(\mathrm{Nm})
$$

$475.3 \pm 115.5 \quad 398.9 \pm 83.9^{*}$

0.03

Absolute peak torque of flexor muscles at $180^{\circ} . \mathrm{s}^{-1}$ in eccentric

$$
\text { action }(\mathrm{Nm})
$$

$120.1 \pm 40.1^{*}$

$<0.01$

Peak torque relative to body mass of flexor muscles at $180^{\circ} . \mathrm{s}^{-1}$

in eccentric action $(\mathrm{Nm})$

2

3

4

5

6

7

8

9

10

11 Data are expressed as mean \pm standard deviation. $* P<0.05$ compared to male runners. 


\section{Table 3(on next page)}

Correlation coefficient ( $P$ value) between isokinetic and anthropometric variables and energy running cost $\left(E_{c}\right)$ for male runners. 
1 Table 3. Correlation coefficient ( $P$ value) between isokinetic and anthropometric variables and energy running cost ( $\left.E_{c}\right)$ for male 2 runners.

\begin{tabular}{|c|c|c|c|c|}
\hline & $\begin{array}{c}\mathbf{E}_{\mathrm{c}} \text { at } 10 \mathrm{~km} \cdot \mathrm{h}^{-1} \text { with } \\
\text { a } 3 \% \text { gradient } \\
(\mathrm{n}=\mathbf{2 4})\end{array}$ & $\begin{array}{c}E_{c} \text { at } 11 \mathrm{~km} \cdot \mathrm{h}^{-1} \text { with a } \\
1 \% \text { gradient } \\
(\mathrm{n}=24)\end{array}$ & $\begin{array}{c}E_{c} \text { at } 12 \text { km.h }{ }^{-1} \text { with } \\
\text { a } 3 \% \text { gradient } \\
(n=9)\end{array}$ & $\begin{array}{c}\mathrm{E}_{\mathrm{c}} \text { at } 14 \mathrm{~km} \cdot \mathrm{h}^{-1} \text { with } \\
\text { a } 1 \% \text { gradient } \\
(\mathrm{n}=9)\end{array}$ \\
\hline \multicolumn{5}{|l|}{ Isokinetic variables } \\
\hline Conventional strength balance ratio & $0.01(0.98)$ & $0.23(0.29)$ & $0.05(0.90)$ & $0.29(0.47)$ \\
\hline Functional strength balance ratio & $-0.29(0.18)$ & $-0.43(0.04)$ & $-0.72(0.04)$ & $0.09(0.82)$ \\
\hline $\begin{array}{l}\text { Absolute peak torque of extensor muscles at } \\
\qquad 60^{\circ} \cdot \mathrm{s}^{-1} \text { in concentric action }(\mathrm{Nm})\end{array}$ & $-0.01(0.97)$ & $-0.01(0.97)$ & $0.56(0.14)$ & $-0.14(0.73)$ \\
\hline $\begin{array}{l}\text { Peak torque relative to body mass of } \\
\text { extensor muscle at } 60^{\circ} . \mathrm{s}^{-1} \text { in concentric } \\
\text { action }(\%)\end{array}$ & $-0.16(0.47)$ & $-0.02(0.92)$ & $0.32(0.43)$ & $-0.14(0.72)$ \\
\hline $\begin{array}{l}\text { Absolute peak torque of flexor muscles at } \\
660^{\circ} \cdot \mathrm{s}^{-1} \text { in concentric action }(\mathrm{Nm})\end{array}$ & $0.01(0.95)$ & $0.08(0.71)$ & $0.61(0.10)$ & $0.01(0.99)$ \\
\hline $\begin{array}{l}\text { Peak torque relative to body mass of flexor } \\
\text { muscle at } 60^{\circ} . \mathrm{s}^{-1} \text { in concentric action (\%) }\end{array}$ & $-0.14(0.50)$ & $0.11(0.60)$ & $0.31(0.44)$ & $0.02(0.96)$ \\
\hline $\begin{array}{l}\text { Absolute peak torque of extensor muscles at } \\
\qquad 180^{\circ} \cdot \mathrm{s}^{-1} \text { in concentric action }(\mathrm{Nm})\end{array}$ & $0.16(0.47)$ & $0.01(0.97)$ & $0.63(0.09)$ & $-0.19(0.64)$ \\
\hline $\begin{array}{l}\text { Peak torque relative to body mass of } \\
\text { extensor muscle at } 180^{\circ} . \mathrm{s}^{-1} \text { in concentric }\end{array}$ & $0.05(0.80)$ & $-0.01(0.97)$ & $0.49(0.21)$ & $-0.21(0.60)$ \\
\hline
\end{tabular}


action (\%)

Absolute peak torque of flexor muscles at $180^{\circ} . \mathrm{s}^{-1}$ in concentric action $(\mathrm{Nm})$

$$
0.10(0.62)
$$

$-0.25(0.25)$

$0.31(0.45)$

$0.02(0.95)$

Peak torque relative to body mass of flexor muscle at $180^{\circ} . \mathrm{s}^{-1}$ in concentric action (\%)

$$
-0.08(0.71)
$$

$-0.10(0.80)$

Absolute peak torque of extensor muscles at $180^{\circ} . \mathrm{s}^{-1}$ in eccentric action $(\mathrm{Nm})$

$0.30(0.16)$

$0.25(0.25)$

$0.72(0.04)$

$-0.16(0.69)$

Peak torque relative to body mass of extensor muscles at $180^{\circ} . \mathrm{s}^{-1}$ in eccentric action (\%)

Absolute peak torque of flexor muscles at $180^{\circ} . \mathrm{s}^{-1}$ in eccentric action $(\mathrm{Nm})$

Peak torque relative to body mass of flexor muscles at $180^{\circ} . \mathrm{s}^{-1}$ in eccentric action (\%) 
Table 4(on next page)

Correlation coefficient ( $P$ value) between isokinetic and anthropometric variables and energy running cost $\left(E_{c}\right)$ for female runners. 
1 Table 4. Correlation coefficient ( $P$ value) between isokinetic and anthropometric variables and energy running cost $\left(\mathrm{E}_{\mathrm{c}}\right)$ for female 2 runners.

\begin{tabular}{lcc}
\hline $\mathbf{E}_{\mathrm{c}}$ at $10 \mathrm{~km} . \mathrm{h}^{-1}$ with a & $\mathbf{E}_{\mathrm{c}}$ at $11 \mathrm{~km} . \mathrm{h}^{-1}$ with a \\
$3 \%$ gradient $(\mathrm{n}=15)$ & $1 \%$ gradient $(\mathrm{n}=15)$ \\
\hline
\end{tabular}

\section{Isokinetic variables}

\begin{tabular}{|c|c|c|}
\hline Conventional strength balance ratio & $0.01(0.98)$ & $0.35(0.25)$ \\
\hline Functional strength balance ratio & $-0.02(0.94)$ & $-0.16(0.60)$ \\
\hline $\begin{array}{l}\text { Absolute peak torque of extensor muscles at } 60^{\circ} . \mathrm{s}^{-1} \text { in } \\
\text { concentric action }(\mathrm{Nm})\end{array}$ & $-0.17(0.59)$ & $0.10(0.75)$ \\
\hline $\begin{array}{l}\text { Peak torque relative to body mass of extensor muscle at } \\
\qquad 60^{\circ} \cdot \mathrm{s}^{-1} \text { in concentric action }(\%)\end{array}$ & $-0.07(0.80)$ & $0.04(0.89)$ \\
\hline $\begin{array}{l}\text { Absolute peak torque of flexor muscles at } 60^{\circ} \cdot \mathrm{s}^{-1} \text { in } \\
\text { concentric action }(\mathrm{Nm})\end{array}$ & $-0.15(0.62)$ & $0.36(0.24)$ \\
\hline $\begin{array}{l}\text { Peak torque relative to body mass of flexor muscle at } \\
\qquad 60^{\circ} . \mathrm{s}^{-1} \text { in concentric action }(\%)\end{array}$ & $-0.04(0.88)$ & $0.36(0.24)$ \\
\hline $\begin{array}{l}\text { Absolute peak torque of extensor muscles at } 180^{\circ} \cdot \mathrm{s}^{-1} \text { in } \\
\text { concentric action }(\mathrm{Nm})\end{array}$ & $0.39(0.19)$ & $0.53(0.07)$ \\
\hline $\begin{array}{l}\text { Peak torque relative to body mass of extensor muscle at } \\
180^{\circ} . \mathrm{s}^{-1} \text { in concentric action }(\%)\end{array}$ & $0.59(0.03)$ & $0.50(0.09)$ \\
\hline $\begin{array}{l}\text { Absolute peak torque of flexor muscles at } 180^{\circ} . \mathrm{s}^{-1} \text { in } \\
\text { concentric action }(\mathrm{Nm})\end{array}$ & $-0.28(0.37)$ & $0.10(0.74)$ \\
\hline $\begin{array}{l}\text { Peak torque relative to body mass of flexor muscle at } \\
\qquad 180^{\circ} \cdot \mathrm{s}^{-1} \text { in concentric action }(\%)\end{array}$ & $-0.27(0.39)$ & $0.06(0.84)$ \\
\hline $\begin{array}{l}\text { Absolute peak torque of extensor muscles at } 180^{\circ} . \mathrm{s}^{-1} \text { in } \\
\text { eccentric action }(\mathrm{Nm})\end{array}$ & $-0.16(0.61)$ & $0.22(0.48)$ \\
\hline $\begin{array}{l}\text { Peak torque relative to body mass of extensor muscles at } \\
\qquad 180^{\circ} \cdot \mathrm{s}^{-1} \text { in eccentric action }(\%)\end{array}$ & $-0.19(0.53)$ & $0.21(0.47)$ \\
\hline $\begin{array}{l}\text { Absolute peak torque of flexor muscles at } 180^{\circ} \cdot \mathrm{s}^{-1} \text { in } \\
\text { eccentric action }(\mathrm{Nm})\end{array}$ & $-0.14(0.64)$ & $-0.12(0.69)$ \\
\hline Peak torque relative to body mass of flexor muscles at & $-0.15(0.60)$ & $-0.11(0.70)$ \\
\hline
\end{tabular}




\begin{tabular}{ccc}
$180^{\circ} \cdot \mathrm{s}^{-1}$ in eccentric action $(\%)$ & & \\
Total body mass $(\mathrm{kg})$ & $-0.24(0.51)$ & $0.09(0.71)$ \\
Fat-free mass $(\mathrm{g})$ & $0.01(0.98)$ & $0.13(0.66)$ \\
Fat-free mass $(\%)$ & $0.38(0.22)$ & $0.21(0.50)$ \\
\hline
\end{tabular}


Figure 1

Positioning assumed by the participant during isokinetic evaluation of the hip.

Photo credit: Marilia S. Andrade.

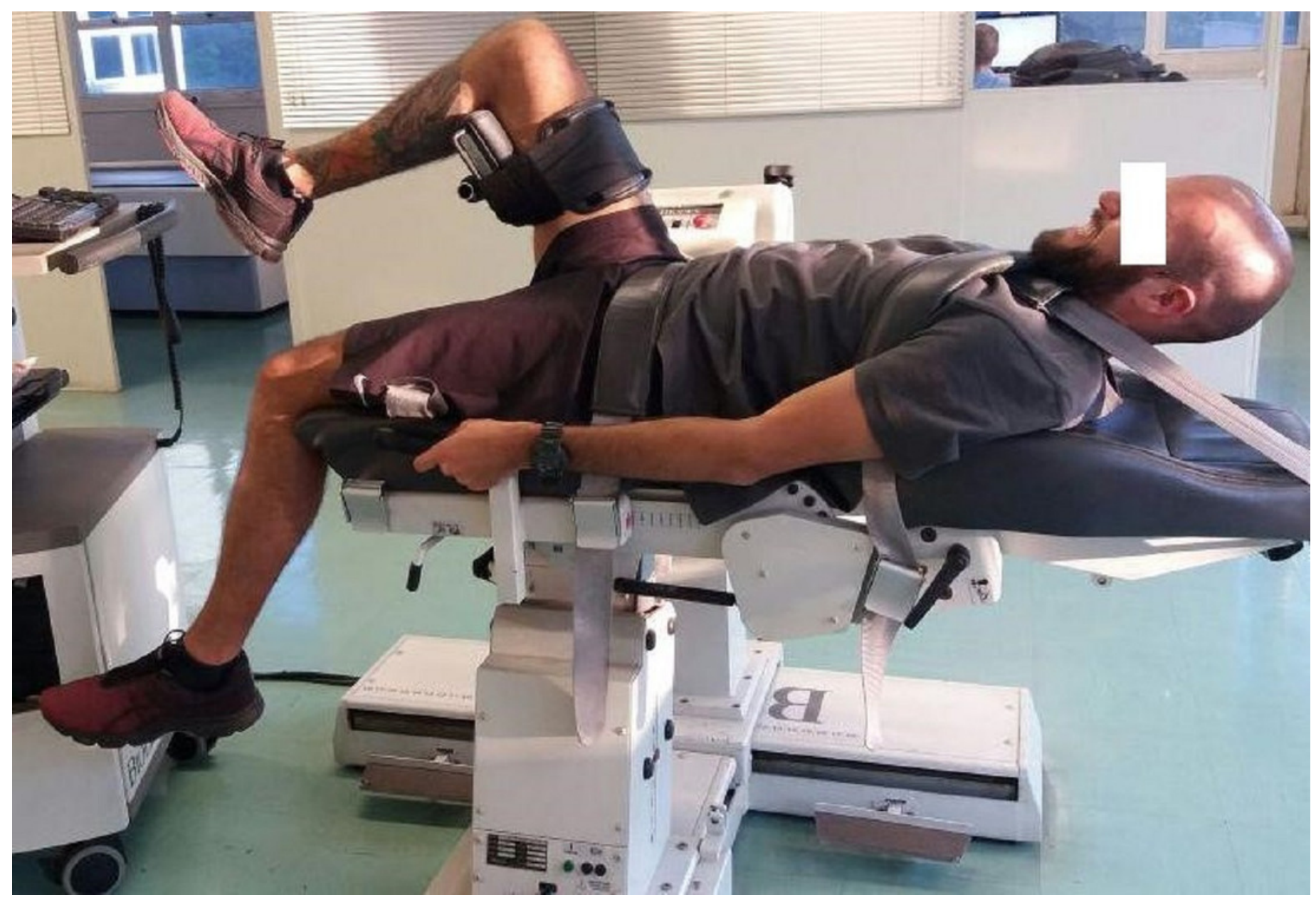

